OSAHS

\title{
Palatal surgery in a transoral robotic setting (TORS): preliminary results of a retrospective comparison between uvulopalatopharyngoplasty (UPPP), expansion sphincter pharyngoplasty (ESP) and barbed repositioning pharyngoplasty (BRP)
}

\author{
La chirurgia palatale all'interno di un setting robotico transorale (TORS): \\ risultati preliminari di uno studio retrospettivo comparativo tra UPPP, ESP e BRP \\ G. CAMMAROTO', F. MONTEVECCH², G. D’AGOSTINO², E. ZECCARDO², C. BELLINI², G. MECCARIELLO², \\ C. $\mathrm{VICINI^{2 }}$ \\ ${ }^{1}$ Department of Otolaryngology, University of Messina, Italy; ${ }^{2}$ Department of Special Surgery, ENT and Oral Surgery \\ Unit, Ospedale Morgagni Pierantoni, Forli, Italy
}

\begin{abstract}
SUMMARY
It has become increasingly clear in the past decade that surgical management of obstructive sleep apnoea hypopnoea syndrome (OSAHS) is most successfully managed with multilevel surgery. We evaluated the outcomes of multilevel interventions comparing three different palatal techniques added to TORS: uvulopalatopharyngoplasty (UPPP), a modified expansion sphincter pharyngoplasty (ESP), inspired by the Pang expansion sphincter pharyngoplasty technique and the latest barbed repositioning pharyngoplasty (BRP). Thirty patients were retrospectively evaluated. Ten patients underwent UPPP by Fairbanks, 10 BRP and 10 a modified ESP already described. All patients underwent TORS, tonsillectomy and septo-turbinoplasty. For all cases, the following data were retrieved and revaluated: preoperative and postoperative apnoea-hypopnoea index (AHI), preoperative and postoperative Epworth Sleepiness Scale (ESS), pain visual analogue scale (VAS; 0-10) for the first 5 days postoperatively, palatal operative time for each surgical technique, discharge date and complication types and rate. Both BRP and ESP resulted in better postoperative AHI values and higher surgical success rates in comparison with UPPP. On the other hand, BRP was not more effective than ESP. ESP surgery time was significantly higher than UPPP, while BRP was the quickest procedure. In summary, ESP and BRP seem to be more effective than UPPP in a multilevel surgical robotic setting. However, being quicker, easy to learn and with a low rate of complications, BRP is a safe, effective and promising option for treatment of OSAHS patients.
\end{abstract}

KEY WORDS: TORS • OSAHS • Palatal surgery

\begin{abstract}
RIASSUNTO
Negli ultimi anni si è diffusa l'opinione che la chirurgia multilivello nel trattamento della sindrome delle apnee ostruttive garantisca risultati pià soddisfacenti. L'obiettivo del nostro lavoro è quello di confrontare tre tecniche palatali associate alla TORS: l'uvulopalatofaringoplastica (UPPP), l'expansion sphincter pharyngoplasy (ESP) e la barbed repositioning pharingoplasty (BRP). Trenta pazienti, trattati con TORS, tonsillectomia e settoturbinoplastica e chirurgia palatale sono stati retrospettivamente studiati. I seguenti valori pre e post-operatori sono stati presi in considerazione: AHI, ESS, VAS per la valutazione del dolore, tempi operatori palatali, data di dimissione e complicanze (tipi ed incidenza). Sia la BRP che l'ESP hanno garantito dei valori postoperatorio di AHI inferiori rispetto all'UPPP con un maggior tasso di successo chirurgico. Dall'altra parte non è stato possibile dimostrare una superiorità della BRP sull'ESP. I tempi operatori più lunghi sono stati registrati nel gruppo ESP mentre i più brevi sono stati riscontrati nel gruppo BRP. Riassumendo, ESP e BRP sono risultate più efficaci dell'UPPP in un setting robotico multilivello. Inoltre, essendo una tecnica rapida, di facile apprendimento e dal basso tasso di complicanze, la BRP si presenta come una valida opzione chirurgica nel trattamento dell'OSAS.
\end{abstract}

PAROLE CHIAVE: TORS • OSAHS • Chirurgia palatale

Acta Otorhinolaryngol Ital 2017;37:406-409

\section{Introduction}

Today, transoral robotic surgery (TORS) for obstructive sleep apnoea-hypopnea syndrome (OSAHS) is a widely recognised effective therapeutic option.
It has become increasingly clear in the past decade that surgical management of OSAHS is most successfully managed with multilevel surgery ${ }^{1-8}$.

In particular, drug-induced sleep endoscopy (DISE) has shown that the hypopharynx and base of tongue are im- 
portant anatomic components of obstruction in OSAHS and therefore must be treated ${ }^{9}$.

During the last decades, several variations in palatal surgery have been proposed. We evaluated the outcomes of multilevel interventions comparing three different palatal techniques added to TORS: uvulopalatopharyngoplasty (UPPP), a modified expansion sphincter pharyngoplasty (ESP), inspired by the Pang expansion sphincter pharyngoplasty technique and the latest barbed repositioning pharyngoplasty (BRP) ${ }^{10-13}$.

\section{Materials and methods}

Thirty patients were retrospectively evaluated. The patients were randomly selected from the dataset including OSAHS patients treated surgically from May 2008 to December 2015 at the ENT unit of the Hospital MorgagniPierantoni, Forlì, Italy. Incomplete or very recent cases, with a postoperative polysomnographic evaluation shorter than 6 months, were excluded. Patients met inclusion criteria if they were 18 years of age or older, had failed continuous positive airway pressure as a nonsurgical treatment alternative and had an apnoea-hypopnoea index (AHI) of 20 or above. Patients who had had prior airway surgery, such as UPPP or tonsillectomy, were not eligible. Preoperative workup also included DISE. Only patients who were found to have significant collapse contemporarily at the retropalatal, retrolingual and hypopharyngeal levels were included. Three groups, each with 10 patients, were compared. Ten patients underwent UPPP by Fairbanks ${ }^{11}, 10 \mathrm{BRP}{ }^{12}$ and 10 a modified ESP already described ${ }^{10}$. All 30 patients were treated with a robotic tongue base reduction with supraglottoplasty (SGP) by Vicini ${ }^{4}$ with temporary tracheostomy, tonsillectomy and septo-turbinoplasty. For all cases, the following data were retrieved and revaluated:

1. age;

2. sex;

3. preoperative BMI;

4. preoperative and postoperative AHI (all sleep studies were carried out in an unattended fashion by means of a Polymesam 8-channel; reviewed and scored by the same expert in sleep medicine according to the American Academy of Sleep Medicine Guidelines $2007^{\text {14; }}$

5. preoperative and postoperative Epworth Sleepiness Scale (ESS), using the Italian version of the Epworth test that was adapted and tested for the Italian-speaking population ${ }^{15}$;

6. pain visual analogue scale (VAS; $0-10)$ for the first 5 days postoperatively;

7. palatal operative time for each surgical technique (excluding tonsillectomy), as measured by our operating theatre electronic system;

8. discharge date;

9. complication types and rate.
The 3 groups were reasonably matched for sex, age, BMI and preoperative AHI. The definition of surgical response and success were a reduction from the preoperative AHI of at least 50\% (response) and less than 20 events per hour (success). All clinical records were reviewed to examine all the differential features between the 3 groups potentially related to the different palate procedures applied.

The study met the approval of the Local Board of Ethics (Institutional Review Board of the Hospital MorgagniPierantoni, Forlì). Statistical evaluation of pre-postoperative changes between groups was performed by means of Mann-Whitney, Kruskal Wallis and Wilcoxon tests, with the latter used to evaluate pre-postoperative changes in each group.

\section{Results}

The 3 groups showed no significant difference in F/M ratio (1/9 in all groups), age, BMI and preoperative AHI (Table I). The AHI decreased significantly after surgery in all groups except UPPP. ESS values, however, decreased significantly postoperatively in all groups (Table II). No significant differences in post-operative pain, deltaAHI (preAHI-postAHI) and hospital stay were recorded (Table III).

Surgical success rate was $90 \%$ in the ESP and BRP groups, and 50\% in the UPPP group. ESP and BRP postoperative AHI values were significantly lower than UPPP. On the other hand, ESP and BRP did not show any differences in this measure. Both ESP and BRP post-operative ESS values were significantly lower than the UPPP figure, while no differences were seen between the first two groups. ESP surgery time was significantly higher than UPPP while BRP was seen to be the quickest procedure (Table IV).

No complications were recorded in any group.

Table I. Pre-operative intergroup analysis.

\begin{tabular}{llllcc} 
& & N & Mean & Std. deviation & P \\
Age & UPPP & 10 & 58.40 & 9.90 & \\
& ESP & 10 & 52.80 & 11.39 & 0.170 \\
& BRP & 10 & 48.20 & 11.39 & \\
& Total & 30 & 53.13 & 11.36 & \\
\hline BMI & UPPP & 10 & 26.79 & 3.72 & \\
& ESP & 10 & 27.03 & 2.12 & 0.181 \\
& BRP & 10 & 28.77 & 2.56 & \\
& Total & 30 & 27.53 & 2.92 & \\
\hline preAHI & UPPP & 10 & 34.04 & 14.03 & \\
& ESP & 10 & 35.59 & 13.87 & 0.953 \\
& BRP & 10 & 37.84 & 21.60 & \\
& Total & 30 & 35.82 & 16.37 & \\
\hline
\end{tabular}


Table II. Intragroup analysis: pre-postoperative variations.

\begin{tabular}{lcccc} 
& Group & Mean & Std. Deviation & P \\
preAHI & & 34.04 & 14.03 & 0.005 \\
postAHI & & 13.53 & 7.76 & \\
preESS & BRP & 10.40 & 2.50 & 0.008 \\
postESS & & 3.90 & 3.57 & \\
\hline preAHI & & 35.59 & 13.87 & 0.005 \\
postAHI & ESP & 9.63 & 9.25 & \\
preESS & & 13.00 & 4.49 & 0.005 \\
postESS & & 4.90 & 3.87 & \\
\hline preAHI & & 37.84 & 21.60 & 0.059 \\
postAHI & UPPP & 22.92 & 13.30 & \\
preESS & 12.30 & 4.24 & 0.021 \\
postESS & 8.50 & 5.42 & \\
\hline
\end{tabular}

\section{Discussion}

In our sleep disorder breathing surgical practice, it is routine to perform multilevel surgery at the same surgical session. In our philosophy, TORS is just a step devised to address tongue base and supraglottic collapse, and is routinely carried out together with nose and palate surgery if required, according to DISE findings.

In the last years, many palatal techniques have been proposed. The introduction of the Pang ESP technique and, more recently, BRP have changed our OSAHS multilevel surgical setting 101213 . These two techniques soon became our first option with the robot-assisted multilevel procedure. Recently, the effectiveness of ESP was demonstrated in a meta-analysis by Pang ${ }^{16}$. Moreover, our group reported on the superiority of ESP in a multilevel setting when compared to UPPP ${ }^{8}$.

However, in a 2015 study by our group it was shown that the BRP technique is feasible, safe and effective in the management of OSAHS patients ${ }^{12}$. The use of a barbed suture allows to perform a quick procedure and to respect mucosal and muscular structures (Figs. 1, 2).

The purpose of the present study was to show the superiority of ESP and BRP compared to traditional UPPP in a multilevel setting, highlighting the advantages of BRP.

Taking into account the retrospective nature of our study and the limited size of the three groups, our preliminary results may be interpreted as follows. Both BRP and ESP resulted in better postoperative AHI values and higher surgical success rate in comparison with UPPP. On the other hand, BRP was not more effective than ESP.

ESP surgery time was significantly higher than UPPP while BRP was seen to be the quickest procedure. Furthermore, in our series no complications were recorded, likely due to the small size of our sample. However, we assume that the probability of bleeding is significantly lower in BRP patients, as the soft palate and the phar-
Table III. Post-operative intergroup analysis (not significant).

\begin{tabular}{llcccc}
\multirow{7}{*}{ Pain } & & N & Mean & Std. Deviation & P \\
& UPPP & 10 & 1.69 & 0.62 & \\
& ESP & 10 & 1.79 & 0.90 & 0.416 \\
& BRP & 10 & 2.79 & 2.02 & \\
& Total & 30 & 2.09 & 1.37 & \\
\hline Hospital stay & UPPP & 10 & 6.70 & 1.25 & \\
& ESP & 10 & 7.10 & 1.52 & 0.811 \\
& BRP & 10 & 7.10 & 3.24 & \\
\hline deltaAHI & Total & 30 & 6.96 & 2.12 & \\
& UPPP & 10 & 20.51 & 12.45 & \\
& ESP & 10 & 25.96 & 13.95 & 0.313 \\
& BRP & 10 & 14.92 & 26.83 & \\
& Total & 30 & 20.46 & 18.78 & \\
\hline
\end{tabular}

Table IV. Post-operative intergroup analysis.

\begin{tabular}{llccc} 
& Group & Mean & Std. Deviation & P \\
palatalTIME & BRP & 15.70 & 2.16 & 0,00 \\
& UPPP & 28.20 & 2.29 & \\
\hline postESS & BRP & 3.90 & 3.57 & 0,019 \\
& UPPP & 8.50 & 5.42 & \\
\hline postAHI & BRP & 13.53 & 7.76 & 0,043 \\
& UPPP & 22.92 & 13.30 & \\
\hline PalataITIME & BRP & 15.70 & 2.16 & 0,00 \\
& ESP & 37.60 & 4.59 & \\
\hline postESS & BRP & 3.90 & 3.57 & 0,62 \\
& ESP & 4.90 & 3.87 & \\
\hline postAHI & BRP & 13.53 & 7.76 & 0,29 \\
& ESP & 9.63 & 9.25 & \\
\hline palataITIME & ESP & 37.60 & 4.59 & 0,00 \\
& UPPP & 28.20 & 2.29 & \\
\hline postESS & ESP & 4.90 & 3.87 & 0,013 \\
& UPPP & 8.50 & 5.42 & \\
\hline postAHI & ESP & 9.63 & 9.25 & 0,019 \\
& UPPP & 22.92 & 13.30 & \\
\hline
\end{tabular}

yngopalatine muscle are respected when performing this technique.

No difference in postoperative pain was recorded between groups, probably because all patients underwent tonsillectomy contemporarily.

The higher effectiveness of BRP and ESP may be interpreted considering their more focused action on the lateral wall area. Moreover, the authors feel that circular scarring and tension produce a significantly delayed reduction of oropharyngeal section in UPPP cases. In ESP, the same scar retraction would probably tend to straighten the angle between the plane of tonsillar fossa and the intrapalatal muscular flap, producing a progressive enlarging vector for the lateral wall and palate. 


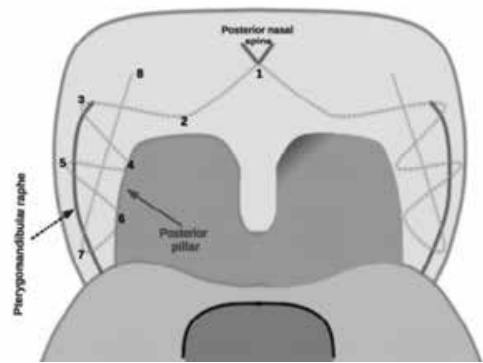

Fig. 1 Descriptive scheme of all BRP steps highlighting the anchoring points for the barbed suture.

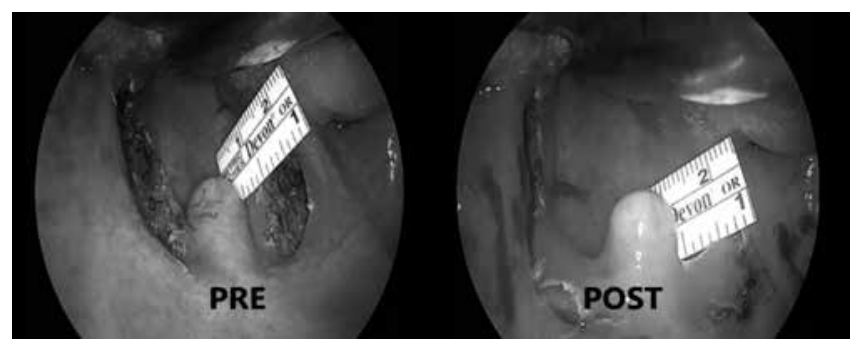

Fig. 2 Pre-operative and post-operative images of a patient treated with a BRP technique: the improvement of the anterior-posterior diameter is shown.

BRP, instead, allows to displace the posterior pillar (palatopharyngeal muscle) in a more lateral and anterior position to enlarge the oropharyngeal inlet as well as the retropalatal space. In a previous study published by our group, it was shown how this technique is easy to learn even for non-experienced surgeons, less time consuming and with no significant complications ${ }^{12}$.

\section{Conclusions}

ESP and BRP seem to be more effective than UPPP in a multilevel surgical robotic setting. Being quicker, easy to learn and with a low rate of complications, BRP appears to be a safe, effective and promising option for the treatment of OSAHS patients.

\section{References}

1 Vicini C, Montevecchi F, Campanini A, et al. (2014) Clinical outcomes and complications associated with TORS for OSAHS: a benchmark for evaluating an emerging surgical technology in a targeted application for benign disease. ORL J Otorhinolaryngol Relat Spec 2014;76:63-9.

2 Hoff PT, D'Agostino MA, Thaler ER. Transoral robotic surgery in benign diseases including obstructive sleep apnea: safety and feasibility. Laryngoscope 2015;125:1249-53.
3 Lee J, Weinstein G, O'Malley B, et al. Transoral robot-assisted lingual tonsillectomy and uvulopalatopharyngoplasty for obstructive sleep apnea. Ann Otol Rhinol Laryngol 2012;121:635-9.

4 Vicini C, Dallan I, Canzi P, et al. Transoral robotic tongue base resection in obstructive sleep apnoeahypopnoea syndrome: a preliminary report. ORL J Otorhinolaryngol Relat Spec 2010;72:22-7.

5 Vicini C, Dallan I, Canzi P, et al. Transoral robotic surgery of the tongue base in obstructive sleep Apnea-Hypopnea syndrome: anatomic considerations and clinical experience. Head Neck 2012;34:15-22.

6 Friedman M, Hamilton C, Samuelson CG, et al. Transoral robotic glossectomy for the treatment of obstructive sleep apnea-hypopnea syndrome. Otolaryngol Head Neck Surg 2012;146:854-62.

7 Meccariello G, Cammaroto G, Montevecchi F, et al. Transoral robotic surgery for the management of obstructive sleep apnea: a systematic review and meta-analysis. Eur Arch Otorhinolaryngol 2017;274:647-53.

8 Vicini C, Montevecchi F, Pang K, et al. Combined transoral robotic tongue base surgery and palate surgery in obstructive sleep apnea-hypopnea syndrome: expansion sphincter pharyngoplasty versus uvulopalatopharyngoplasty. Head Neck 2014;36:77-83.

9 De Vito A, Carrasco Llatas M, Vanni A, et al. European position paper on drug-induced sedation endoscopy (DISE). Sleep Breath 2014;18:453-65.

10 Pang KP, Woodson BT. Expansion sphincter pharyngoplasty: a new technique for the treatment of obstructive sleep apnea. Otolaryngol Head Neck Surg 2007;137:110-4.

11 Fairbanks DN. Operative techniques of uvulopalatopharyngoplasty. Ear Nose Throat J 1999;78:846-50.

12 Vicini C, Hendawy E, Campanini A, et al. Barbed reposition pharyngoplasty (BRP) for OSAHS: a feasibility, safety, efficacy and teachability pilot study. "We are on the giant's shoulders”. Eur Arch Otorhinolaryngol 2015;272:3065-70.

13 Mantovani M, Minetti A, Torretta S, et al. The velo-uvulopharyngeal lift or "roman blinds" technique for treatment of snoring: a preliminary report. Acta Otorhinolaryngol Ital 2012;32:48-53.

14 Morgenthaler T, Alessi C, Friedman L, et al. Practice parameters for the use of actigraphy in the assessment of sleep and sleep disorders: an update for 2007. Sleep 2007;30:519-29.

15 Vignatelli L, Plazzi G, Barbato A, et al. Italian version of the Epworth sleepiness scale: external validity. Neurol Sci 2003;23:295-300.

16 Pang KP, Pang EB, Win MT, et al. Expansion sphincter pharyngoplasty for the treatment of OSA: a systemic review and meta-analysis. Eur Arch Otorhinolaryngol 2016;273:2329-33. 